\title{
MIGRAÇÕES INTERNACIONAIS NÃO-DOCUMENTADAS
}

\section{UMA TENDÊNCIA GLOBAL CRESCENTE}

\author{
Graeme Hugo* \\ Traduzido do inglês por: \\ Tatiana Schor e Carlos de Almeida Toledo
}

\section{INTRODUÇÃO}

A Globalização é um dos fenômenos mais difundidos do fim dos anos noventa e associado a ele, fluxos financeiros, bens e informações cruzam fronteiras nacionais em volumes nunca antes verificados. Globalização e redução massiva dos custos reais de viagem têm mostrado também um aumento na escala e complexidade no movimento de pessoas entre nações. Entretanto, as barreiras oficiais erguidas por Estados Nações para o influxo de pessoas têm sido mais resistentes ao processo da globalização do que as barreiras aos fluxos de informações, movimentos financeiros e mercadorias. Contudo, as desigualdades, diferenças e complementaridades internacionais que propiciaram os outros fluxos são impingidos de forma igualmente forte sobre as pessoas. Diante das barreiras impostas à entrada nos países, as migrações internacionais, aquelas que acontecem à margem dos sistemas oficiais de controle, crescem exponencialmente. De fato, pode parecer que exista pelo menos a mesma quantidade de migrantes internacionais ilegais quanto migrantes oficialmente reconhecidos. Entretanto, quase toda a pesquisa e literatura disponiveis sobre padrões, causas e conseqüências das migrações internacionais dedicam-se à consideração dos migrantes legalmente documentados; fato que não surpreende dadas as dificuldades inerentes em medir as migrações não-documentadas, sem men- cionar aqui as dificuldades em estudá-las detalhadamente.

O objetivo deste artigo é o de rever uma série de itens atinentes à situação global contemporânea das migrações internacionais ilegais. Faz-se alguns breves comentários acerca da definição de migrações não-documentadas, bem como com relação à sua medida. Tenta-se indicar, no limite do possível, a partir dos poucos dados disponíveis, a escala e o padrão espacial das migrações não-documentadas através de uma região do mundo, a Ásia, na última metade dos anos 90 . Temse, então, um resumo das principais causas da migração ilegal no limite que estas diferem das causas do movimento legal. Alguns dos principais itens políticos associados às migrações não-documentadas são discutidos na seção final.

\section{CARACTERISTICAS DOS DADOS E DEFINIÇÕES}

A migração internacional não-documentada é um movimento que acontece à margem das regulações oficiais do governo do país de origem do migrante e/ou de destino. Pode ocorrer de várias formas:

* Os migrantes podem entrar de uma maneira clandestina, não passando pelos pontos oficiais de controle da migração;

*Os migrantes podem entrar de uma maneira legal e ultrapassar o período ao qual teriam direito de residir em um país;

*Os migrantes podem entrar em um país legalmente, mas sob certas condições (ex.: não trabalhar), sem depois respeitar tais condições.

Em geral, migrantes não-documentados são trabalhadores, porém, existem circunstâncias em que as pessoas migram ilegalmente por razões políticas ou para acompanhar membros da família.

Obviamente, se a migração é não-documentada, os dados oficiais com relação a ela serão limitados. A maneira principal pela qual as migrações ilegais em suas características e volume têm sido estimadas, estão discutidas em outro lugar (Bilborrow et al. 1997) e inclui o seguinte: *Muitos países com um número significativo de migrantes ilegais promovem anistias periódicas permitindo aos migrantes não-documentados ganhar algum status oficial no país. O mais conhecido desses casos aconteceu nos Estado Unidos em 1986 e resultou em quase 3 milhões de migrantes regularizados (Martin e Widgren, 1997).

*Se os países mantêm registros tanto de saída quanto de entrada de pessoas, então é possível obter uma informação sobre a permanência ilegal pela comparação entre os documentos de entrada e saída. A Austrália e o Japão, por exemplo, podem estimar taxas de permanência usando tais métodos (Hugo, 1994). 
*Países que fazem consideráveis esforços em encontrar e deportar migrantes não-documentados possuem dados que podem ser indicativos da escala do movimento em direção aos mesmos.

*A comparação entre o censo ou pesquisa nacional com as estatísticas oficiais de imigração pode ser utilizada para estimar migrações ilegais.

*Em alguns contextos as embaixadas mantêm anotações sobre seus compatriotas presentes no país, apesar de muitos serem não-documentados. Por exemplo, em 1997 a embaixada da Indonésia em Kuala Lumpur registrou 1,4 milhões de compatriotas para votar nas eleições nacionais, apesar do número oficial de trabalhadores imigrantes da Indonésia na Malásia ter sido inferior a $10 \%$ de tal quadro (Azizah, 1997).

*Estimativas podem ser obtidas através de organizações de trabalhadores ou empregadores e empresas de recrutamento e viagem envolvidas em migrações ilegais.

*Um leque de métodos de pesquisa está à disposição. Um dos mais inovadores está sendo utilizado pelo México. Envolve a identificação dos principais pontos de imigração ilegal ao longo da fronteira com os EUA, e a realização regular de entrevistas nestes pontos(Bustamante, 1997).

Na realidade, estudar migrações nãodocumentadas requer, via de regra, a obtenção de informações de um largo leque de fontes para, através de uma "triangulação", montar um quadro do que está acontecendo. O estudo direto da migração ilegal pode ser difícil pois os migrantes são, compreensivelmente, ressabiadosem fazer qualquer contato com a oficialidade. Além disso, o envolvimento crescente do crime organizado na movimentação ilícita e/ou contrabando de gente, bem como na área de migração nãodocumentada, pode tornar o estudo deste fenômeno perigoso em si.

\section{PADRÕES DE MIGRAÇÕES NÃO-DOCUMIFNTADAS}

$\mathrm{O}$ cálculo do número de migrantes ilegais pelo mundo é uma tarefa desanimadora. As Nações Unidas (1997) estimaram que em 1990, aproximadamente 120 milhões de pessoas estavam vivendo fora de seu país de origem, ou 2,3\% da população mundial. Estas cifras têm como pretenção incluir migrantes não-documentados, mas pareceriam significativamente subestimadas ao lado das estimativas da situação no momento atual, fim dos anos 90. Nesta seção revisaremos, brevemente, a evidência com relação às migrações ilegaisem um dos maiores sistemas mundiais de migração para demonstrar o significado do movimento não documentado. Não há espaço suficiente neste artigo para compreensivelmente enfocar a situação de cada sistema de migração do mundo, mas os padrõese tendências na Ásia são indicativos dos demais.

A Ásia, detentora de aproximadamente $56 \%$ da população mundial, representa o maior potencial de reserva de migrações internacionais e muito da migração ilegal do mundo ocorre dentro ou origina-se na Ásia (Hugo, 1995). A China sozinha tem mais de um quinto da população do mundo e existem consideráveis pressões migratórias causando um movimento dentro deste vasto país mas também para fora dele, tanto legal quanto ilegalmente. Estima-se que as mudanças estruturais no sistema econômico e político da China criaram 150 milhões ou mais de "trabalhadores em excesso" (Roberts, 1997) e que sua força de trabalho sofre um incremento anual da ordem aproximada de $15 \mathrm{mi}$ lhões.

Embora na China a emigração legal, tanto de migrantes trabalhadores (Saywell, 1997) quanto de colonizadores permanentes (Zeng, 1998), esteja aumentando, verifica-se que é o movimento dos ilegais o mais expressivo. Este movimento chamou a atenção mundial em 1993 quando o cargueiro enferrujado Golden Venture deu voltas em Nova Iorque e foram encontrados 281 chineses que pagaram para serem contrabandeados para dentro dos Estados Unidos ( Newsweek, 21 junho, 1993). Entre os dias 24 de maio e 7 de junho de 1993 (Straits Times, 9 julho, 1993) oito navios foram interceptados pela Guarda Costeira Norte Americana com quase 2 mil estrangeiros chineses ilegais a bordo, e oficiais americanos estimam que contrabandeadores de estrangeiros trazem por volta de cem mil chineses não-documentados para os Estado Unidos anualmente. Eles viajam não só por navio, mas também de avião e por terra através do México. Porém, esta é só uma parte dos fluxos clandestinos de chineses, a maioria deles vem através do olhar favorável dos sindicatos criminaiscom os "snakeheads", os cabeças de cobra, (agentes contrabandeadores de pessoas) cobrando entre US $\$ 20.000$ e US\$50.000 por pessoa. Alguns desses fluxos envolvem:

* Um fluxo significativo para Taiwan, atravésdos $150 \mathrm{~km}$ do Estreitode Taiwan, dos quais uma média de 500 por mês são pegos pela polícia, tendo sido seu número, em 1993, estimado na casa dos $36 \mathrm{mil}$ (Far Eastern Economic Review, 5 agosto, 1993, p.24).

* Movimento através da fronteira norte para dentro da Rússia. A estimativa de chineses morando no Extremo Oriente Russo está entre 200 mil e 2 milhões sendo que a segunda cifra provavelmente está mais próxima do real, porém só existem entre 10 mil e 15 mil trabalhadores chineses legalmente trabalhando na Rússia (Current Digest of the Post Soviet Press, 11 junho, 1997).

* Existem relatos que as Triades Chinesas (Chinese Triads) se juntaramà Máfia italiana para contrabandear estrangeiros (principalmente chineses) para a Itália e Europa e estima-se que existam em torno de 20 mil chineses ilegais na Itália (Straits Times, 23 junho, 1997).

*O contrabando de chineses para o Japão através de sua enrugada costa oeste com a cooperação dos snakeheads chineses e os sindicatos do crime japoneses conhecidos como Yakuza (Inter Press Service, 2 abril, 1997)

* Existe um fluxo significativo para a Birmânia, pelo sul. Em Mandalay, no norte da Birmânia, os chineses da região do Yunnan estão comprando lojas, restaurantes, hotéis e bares de karaokê - até cidadania. "Quando uma pessoa morre em Mandalay sua carteira de identidade é vendida a um negociador do outro lado da fronteira em Ruili que a revende. A foto é então trocada e o novo dono tornase um cidadão birmanês que pode permanecer e comprar propriedades na 
Birmânia' explica um chinês em Ruili. (Linter, 1997, 58).

* Defato, no rio Mekong foi desenvolvido um significativo canal para migração chinesesa ilegal para dentro da Tailândia e de lá para um vasto espectro de países ocidentais (Linter and Saen, 1994, 26). Uma dimensão deste movimento é a venda de meninas chinesas de Yunnan para a prostituição na Tailândia (Gooi, 1993, 36).

Tem havido também fluxos de movimento de chineses ilegais para Hong Kong e que parece ter continuado apesar da unificação com a China em 1997. A origem de muita da migração chinesa ilegal, especialmente direcionada para os Estados Unidos é da Província de Fujian (Mooney et al. 1993, 17).

Em outras partes da Ásia, a migração ilegal também é consideravelmente significante. Desde 1970, diferenças crescentes na velocidadee extensão do declínio da fertilidade, em países asiáticos, têm fomentado enormes diferenças entre as nações, nas taxas em que seu contingente de força de trabalho está aumentando; e, quando isto se combina com as enormes diferenças nas taxas de crescimento econômico e níveis médios de salários, as pressões para migração através da região passam a ser consideráveis (Hugo, 1998). Contudo, leis de imigração severas, em muitas das nações com carência de mãode-obra têm resultado em aumento significativo do movimento de não-documentados (Prasai, 1993).

O Japão tem experimentado significativas carências de mão-de-obra durante a última década (Spencer, 1992), porém tem mantido severas leis de imigração. Ainda assim, o número de estrangeiros legalmente presentes no Japão é mais de um milhão e o número de trabalhadores migrantes ilegaisé atualmente estimado em 285 mil (Japan Economic Newswire, 28 abril, 1997). Muitos trabalham em empregos não especializados e de baixos salários rejeitados pela juventude japonesa (Sassen, 1993) e a maioria vem da Tailândia, Filipinas, Malásia, Coréia do Sul, China, Irã, Birmânia e do Peru. Um elemento expressivo no fluxo de entrada é o de mulheres jovens (vindas principalmente das Filipinas e Tailândia), que ingressam na denominada indústria de anfitriãs. Não obstante esse grupo represente um número de 150 mil, elas são, em alguns casos, vendidas em condições de quase escravidão (Hugo, 1997a).

* A Coréia do Sul tem também déficits de trabalho consideráveis especialmente nas áreas não especializadas e tem regulações de imigrações rígidas apoiadas pela opinião pública, fortemente a favor da manutenção da homogeneidade étnica e social na nação. Estima-se que 130 mil, dos 230 mil trabalhadores estrangeiros na Coréia do Sul, são ilegais (Korean Herald, 28 agosto, 1997). Os principais lugares de origem desses trabalhadores não-documentados eram as Filipinas, China e o Nepal.

* Em Taiwan houve maior facilidade para aceitar trabalhadores migrantes. Foi estimado que no início dos anos 90 existiam 60 mil trabalhadores migrantes ilegais em Taiwan, principalmente da Malásia, Filipinas e Tailândia mas também de tão longe quanto o Paquistão e Gana. Entretanto, uma anistia em 1991 viu a metade deles legalizados (Straits Times, 2 março, 1991). Mais recentemente relatou-se que $12 \%$ dos $248 \mathrm{mil}$ migrantes trabalhadores em Taiwan se tornaram ilegais por terem abandonado seus empregadores e contratos (Migrant News, vol.4,n'11, 1997, p.23).

* Em Hong Kong 23 mil estrangeiros ilegais foram apreendidos em 1996, a maioria deles sendo chineses. Com a devolução de Hong Kong em 1997, a repatriação de trabalhadores chineses detectados como ilegais em Hong Kong continuou (Migrant News, vol.4, $\mathrm{n}^{\circ} 11$, 1997, p.19).

* A Tailândia tem aparecido proeminentementecomouma fonte de migrantes ilegais para outras nações, mas agora é também alvo para migrantes. Registrouse 372 mil trabalhadores migrantes e entre 600 mil e um milhão de ilegais (Asian Migration News, 31 agosto, 1997). Estes são predominantemente de Myanmar, Cambodja e Laos eum número menor da Índia, Bangladesh, Nepal, Sri Lanka e China. Tendem a trabalhar por mais baixos pagamentos, empregos sujos, perigosos e difíceis, na pesca, mineração, agricultura, construção e fá- bricas.

*A malásia tornou-se um dos países com maior número de imigrantes do mundo, com mais de 2 milhões de estrangeiros residindo e trabalhando em um país com apenas 20 milhões de habitantes. Desses, mais da metade são ilegais e aqueles da vizinha Indonésia são o maior grupo (Hugo, 1993). De fato, durante as eleições de 1997 na Indonésia, a Embaixada Indonesiana em Kuala Lumpur registrou 1,4 milhões de votantes (Azizah, 1997). As Filipinas e a Tailândią são também fontes expressivas de imigrantes ilegais, apesar de alguns países sulasiáticos estarem ganhando proeminência.

* Singapura tornou-se crescentemente dependente de trabalhadores estrangeiros, estimados em 570 mil(Hugo, 1997b) dos quais talvez $10 \%$ são ilegais. Singapura não fornece dados oficiais sobre trabalhadores migrantese tem uma política extremamente rígida neste aspecto. Nos anos recentes, por exemplo, houve muita controvérsia sobre chibatadas em migrantes ilegais detectados no país e repatriação em massa de migrantes não-documentados (Sullivan et al.1992). Há também significativa migração circular não-documentada e comutação para Singapura da vizinha Indonésia e Malásia.

* O sul-asiático paquistanês tem registrado 1,5 milhões de imigrantes ilegais, o grosso deles sendo de Bengalis, de Bangladesh, indianos, iranianos, birmaneses e afegãos (Dawn, 20 de agosto, 1997). Concentram-se especialmente na cidade de Karachi que estima-se ter até um quinto de seus 10 milhões de residentes como migrantes ilegais (Deutsche Presse Agentur, 22 fevereiro, 1995).

O exemplo asiático é um indicativo do crescente papel da migração internacional ilegal pelo mundo. Apesar de não podermos tratar aqui em detalhe cada um dos principais sistemas migratórios do mundo, vale mencionar alguns exemplos. Obviamente que os fluxos ilegais mais bem documentados têm sido os dos Estados Unidos. Apesar de aproximadamente 3 milhões de estrangeiros ilegais terem recebido residência permanente (Hoefer, 1989) 
sob o Ato de Reformae Controle Imigratório (IRCA - Immigration Reform and Control Act - 1986), a migração não-documentada continua. O serviço Norte Americano de Imigração e Naturalização estimou, em outubro de 1996, cerca de 5 milhões de estrangeiros não autorizados nos Estados Unidos incluindo 2,7 milhões de mexicanos, 335 mil salvadorenhos, $165 \mathrm{mil}$ guatemaltecos, 120 mil canadenses e 105 mil haitianos. Em 1997, quase 1,7 milhões de estrangeiros ilegais foram apreendidos, sendo $98 \%$ deles mexicanos. Além disso, estima-se um contingente de aproximadamente 2 milhões de migrantes circulares altamente móveis, não-autorizados, que transitam entre o México e os Estados Unidos (Lowell, 1992).

A Europa também tem sido um local de destino importante para as migrações nãodocumentadas; nas estimativas da ILO(International Labour Office) existem 2,6 milhões de estrangeiros não-autorizados nos países da C.E. (Migrant News, vol.4, n'6, 1997). Calcula-se que o número de estrangeiros ilegais na França esteja entre 500 mil e um milhão, enquanto na Itália o número varia entre $250 \mathrm{mil}$ e 800 mil (Migrant News, vol.4, $\mathrm{n}^{\circ} 11,1997$ ), e esteja por volta de $100 \mathrm{mil}$ na Inglaterra (The Guardian, 28 setembro, 1993). No Leste Europeu, presume-se que existam entre 500 mil e um milhão de migrantes ilegais na Rússia (Migrant News, vol.4, $\left.\mathrm{n}^{\circ} 1,1997\right) ; 100$ mil na República Tcheca (Migrant News, vol. 4, ${ }^{\circ} 7,1997$ ) e 300 mil na Ucrânia (Migrant News, vol. 3, nº, 1996).

Os Países do Conselho de Cooperação do Golfo transformaram-se em um importante foco de trabalhadores migrantes desde o início dos anos 70, especialmente de outros países do Oriente Médio e da Ásia. O maior fluxo tem sido para a Arábia Saudita e é lá também que tem havido a mais significativa migração ilegal, com a estimativa de 700 mil estrangeiros nãoautorizados (Migrant News, vol. 4, $\mathrm{n}^{\circ} 11$, 1997, p.23). A Indonésia sozinha teve 25 mil migrantes ilegais repatriados (a maioria deles sendo mulheres) e estima-se que mais 150 mil ainda permaneçam na Arábia Saudita (Jakarta Post, 10 novembro, 1997). NosEmirados Árabes, em 1996, uma onda de batidas policiais sobre os estrangeiros ilegais repatriou 200 mil asiáticos (Migrant News, vol. 4, nº11, 1997, p.24). Em Israel tem-se relatado que existem por volta de 300 mil trabalhadores estrangeiros - sendo dois terços ilegais (Jerusalem Post, 20 junho, 1997).

Pouco se sabe da migração ilegal na África, embora muitas fronteiras nacionais sejam artefatos coloniais cortando regiões étnicas e grupos familiares, o que significa que existe um grande movimento pelas fronteiras que não é registrado pelos canais oficiais. Na África do Sul estima-se que existam entre 2,5 milhões e 4,1 milhões de estrangeiros ilegais (Financial Times, 13 junho, 1997)

\section{O PROCESSO IMIGRATÓRIO NÃO-DOCUMENTADO}

O processo de migrações internacionais não-documentadas é de muitas maneiras parecido com o da migração documentada. É largamente impelida por considerações econômicas, tanto em termos macro quanto micro, é fortemente moldada por redes existentes de migrações sociais e ligações políticas e econômicas tanto históricas quanto contemporâneas entre países (Massey et al. 1993). Entretanto, a ilegalidade do movimento leva a algumas considerações adicionais (Todaro, 1986):

* o migrante tem que considerar a probabilidade de ser detectado, preso e deportado, portanto, de perder muito de seu capital investido na migração.

* a ilegalidade de seu status no destino torna o migrante mais vulnerável à exploração de vários tipos (salários mais baixos, assédio sexual, longas horas de trabalho, más condições) porque ele não pode denunciar os maus tratos às autoridades locais.

Permanecendo os outros fatores iguais, o migrante ilegal incorre em maior risco de voltar prematuramente para casa, de ganhar menos e de submeter-se a condições piores em comparação com seus pares documentados. Em muitos casos, os migrantes não têm a possibilidade de escolha entre os meios ilegais e legais de movimento, dadas as rígidas regulações de imigrações impostas pelos Estados Nações. No entanto, existem situações onde as opções de migração legal estão disponíveis e muitos migrantes continuam a entrar nos paises de forma não documentada (ex. ver Hugo, 1995). Isto aponta para a grande complexidade do processo de migração ilegal.

Torna-se claro, pela seção anterior, que o gradiente de migrações não-documentadas, como dos movimentos legais, sejam de economias mais pobres, com excesso de mão-de-obra e baixos salários, para as economias melhores, com déficit de mão-de-obra e salários mais elevados. Neste sentido, tanto as teorias econômicas de migrações neoclássicas quanto as teorias de economia familiar (household economics) são relevantes em ambos os casos (Massey et al. 1993). Entretanto, existem algumas teorias de migração internacional que parecem ter uma importância particular na compreensão do movimento ilegal, embora também sejam significativas na explicação das migrações legais.

A primeira dessas teorias é a teoria do mercado de trabalho segmentado de Priore (1979). Esta sugere que a migração tende a concentrar-se em mercados de trabalho particulares, geralmente nos de baixa remuneração (sujos, perigosos, difíceis), ocupações de baixo status que são rejeitados pelos nativos. Estas economias de enclave geralmente envolvem atividades nas quais a regulamentação e controle do governo é mínima e é possível que migrantes ilegais sejam absorvidos sem serem facilmente percebidos pelos oficiais.

É também particularmente importante na compreensão da migração ilegal a teoria social de rede. Esta sugere que a maioria dos migrantes (legais e ilegais) movem-se em um contexto de relativa certeza, pelo fato de terem parentes e amigos estabelecidos no destino que os ajudarão a ajustar-se, achar um emprego e assentarse. A existência deste capital social no destinoéum fator poderoso, influenciando a decisão de quem vai ou não se mover e também explica porque algumas comunidades têm alto nível de emigração, enquanto outras, com um contexto econômico aparentemente similar, têm pouca emigração. Argumenta-se aqui que, enquanto as redes sociais são importantes na 
modelação de padrões de migrações legais, estas são elementos absolutamente cruciais em quase todas as migrações nãodocumentadas. Seria, na maioria dos contextos, muito difícil para um migrante não-documentado evadir-se da detectação e se ajustar com sucesso sem a assistência de uma comunidade de migrantes anteriores no destino.

Um dos elementos mais negligenciados na explicação das migrações internacionais está relacionado com a tal indústria da imigração (Hugo e SinghanetraRenard, 1991). Este crescente grupo é formado por instituições, formais e informais, que se desenvolveram pelo mundo unicamente para encorajar, iniciar e facilitar a migração internacional. Incluem agentes de recrutamento, emprestadores de dinheiro, providenciadores de viagem, agentes de todos os tipos, advogados, oficiais do governo, etc., que estão diretamente envolvidos nos vários estágios do processo migratório. Muitos engajados nesta indústria operam dentro da lei, mas um número maior está envolvido na expedição da migração não-documentada. De novo essas instituições são importantes em todas as migrações internacionais (Gost and Lindquist, 1995), porém, são um elemento decisivo em quase todas as migrações não-documentadas. O coyote no México, os cabeças-de-cobra na China e os "calo" na Indonésia têm seus equivalentes em todos os principais fluxos de migrações ilegais pelo mundo afora. Os serviços que eles oferecem são variados: oferta de documentos falsos para a viagem, obtenção de um trabalho para o migrante no destino, acomodação no local de chegada, empréstimo de dinheiro para a viagem, facilitação do retorno das remessas, etc. A indústria tem, via de regra, sofrido de uma má fama em virtude da exploração que geralmente sofrem os trabalhadores - cobrança excessiva, o não cumprimento da promessa de emprego, exploração sexual das mulheres, trapaça para com os trabalhadores com relação aos seus ganhos, a falha em providenciar os serviços prometidos, transporte não seguro e superlotado, etc. Isto, obviamente, não é a experiência de todos os migrantes, mas a imprensa dos países de origem e de destino está repleta com essas histórias de grande sofrimento humano pelo qual o migrante ilegal passa, geralmente por causa da atividade das pessoas e das instituições envolvidas na facilitação do processo migratório. Além do que, parece que o crime organizado penetrou o setor ilegal da indústria da imigração (Beare, 1997; Smith, 1997). Existem enormes lucros a serem obtidos, como pode ser visto pela escala de pagamento feito por pessoas contrabandeadas para dentro dos Estado Unidos no início dos anos 90, como mostra a Figura 1.

Martin e Widgren $(1997,29)$ estimam que o tráfico de pessoas gera um negócio de US\$ 7 bilhões por ano. De acordo com isto, conforme foi discutido na seção anterior, existem evidências das Triads Chinesas, da Yakusa Japonesa e da Máfia Italiana estarem crescentemente envolvidas no contrabando de pessoas. De fato, na Ásia tem sido sugerido que alguns dos grupos criminais organizados envolvidos no comércio ilícito de drogas tem diversificado suas atividades para o contrabando de pessoas e tráfico de mulheres e crianças (Skrobanek et al. 1997). O ponto crucial aqui é que, enquanto os agentes e integrantes da indústria da imigração têm sido fortemente envolvidos na facilitação da migração legal, eles têm sido mais importantes na iniciação e encorajamento da migração de ilegais. Em muitos casos a migração ilegal poderia não estar acontecendo sem o papel chave de intermediários de vários tipos. Eles devem ocupar uma posição central em qualquer teoria, explicando a migração não-documentada.

Outra teoria da migração internacional de particular relevância para o movimento ilegal é a teoria do sistema mundo (Massey et al. 1993). Esta sugere que o movimento populacional está encorajado a acontecer entre países com ligações criadas por envolvimento prévio político e econômico. Logo, as migrações de vietnamitas e coreanos para os Estado Unidos estão relacionadas com o envolvimento deste país em guerras com estas duas nações; a migração para a França da África Francofônica está relacionada com o papel colonial da França nestas nações. Isto certamente se aplica também para os imigrantes ilegais. Sassen (1993) mostrou, por exemplo, que a migração ilegal para o Japão pode estar relacionada à substancial penetração econômica, social, cultural e política nos outros países asiáticos. Logo, os principais influxos são da Malásia, Filipinas, etc., onde o envolvimento da economia japonesa tem sido significativo. Isto também pode ser aplicado aos movimentos migratórios mais recentes para a Coréia do

Figura 1: Custos para Contrabandear uma pessoa para os Estados Unidos incluindo documentação falsa.

Preços estimados
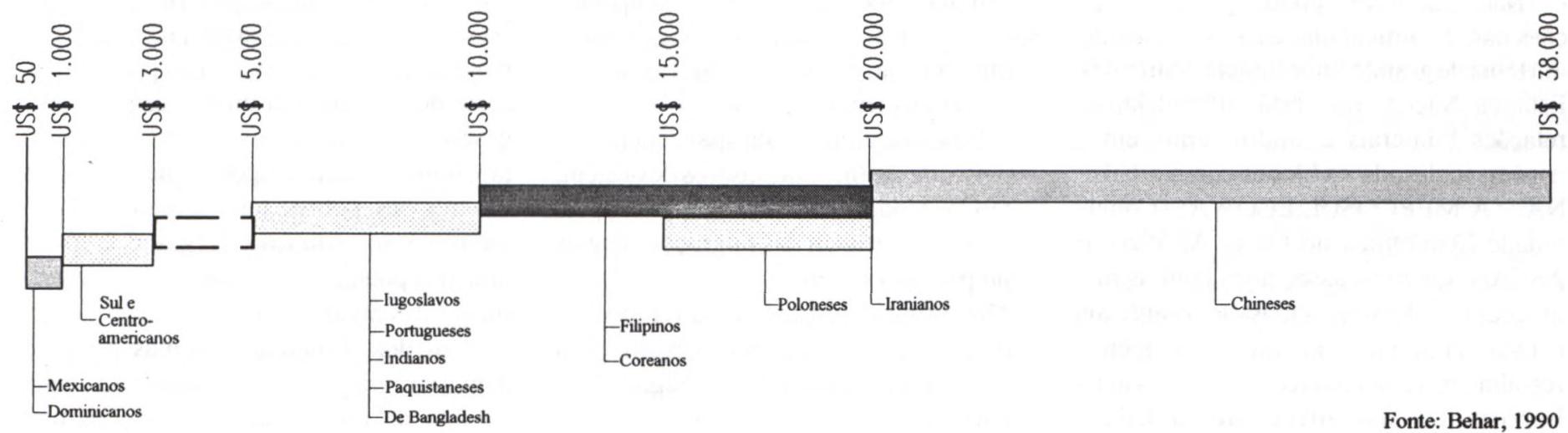

Fonte: Behar, 1990 
Sul e Taiwan desde que estes expandiram seus investimentos no Sudeste Asiático durante a última década. As ligações econômicas criadas pelos investimentos da Coréia do Sul e Taiwan em países como a Tailândia, Malásia e Filipinas têm tido um efeito que influencia os fluxos migratórios recíprocos na direção oposta.

É também evidente que as explicações da causalidade cumulativa são relevantes para entender os determinantes da migração ilegal (Massey et al. 1993). Uma vez que se estabelece o elo migratório, desenvolve-se um impulso através do qual a migração se torna uma atividade normal e esperada. Por exemplo, em algumas aldeias no Oeste de Flores, Indonésia, espera-se que a maior parte dos homens jovens passem algum tempo como migrantes ilegais em Sabah (Hugo, 1996).

A explicação da migração ilegal, tal como suas equivalentes legais, é melhor aproximada através de considerações de uma combinação de teorias, dado que nenhuma teoria particular oferece uma explicação compreensível e aceitável por si só (Massey et al. 1993). Entretanto, sugere-se aqui que na consideração das migrações ilegais existem diferenças ao nivel da significação de teorias particulares em atingir uma explicação compreensiva dado o maior risco envolvido na migração ilegal. Em particular as redes sociais e a indústria da imigração, enquanto importantes na explicação da imigração legal, tornam-se fundamentais para a análise de muitas das migrações ilegais.

\section{CARACTERISTICAS DA MIGRAÇÃO NÃO-DOCUIMENTADA}

Não pode haver dúvida que as migrações não-documentadas estão se tornando um tema de grande importância dentro dos Estados Nações que está influenciando relações bilaterais e multilaterais entre nações, incluindo os blocos como a C.E., NAFTA, MERCOSUL,ECOWAS (Comunidade Econômica do Oeste Asiático) e ASEAN. Os itens associados com as migrações não-documentadas são complexos e toda tentativa feita aqui visa apenas ressaltar brevemente as considerações mais importantes das principais políticas adotadas.

Sem dúvida, o fato da migração ser não-documentada significa que será, viade-regra, vista como um problema pelo país de destino, e é objeto de inúmeras intervenções políticas e programáticas para reduzí-la em escala. Consequentemente, os países têm posto em prática diversas e custosas medidas de controle imigratório (ex: ver Azizah, 1997; Martin e Widgren, 1997) tais como:

* aumento do número de pessoas envolvidas nas atividades de patrulhamento de fronteira;

* construção de barreiras físicas tais como as cercas em construção ao longo das fronteiras México-EUA e MalásiaTailândia;

* sanções sobre os empregadores de migrantes ilegais;

* "batidas policiais" envolvendo um batalhão de oficiais para checar os documentos das pessoas nas áreas conhecidas por terem um número significativo de migrantes ilegais;

* multa e outras punições (ex: espancamento) de migrantes ilegais encontrados.

Entretanto, a experiência tem sido de que enquanto as estratégias dos "fins de destino" têm sucesso limitado no curto prazo, sua efetividade no controle da migração no longo prazo é questionável. Por exemplo, nos Estados Unidos o aumento dessas atividades que fizeram parte da Legislação (IRCA) de 1986 (Espenshade, 1990) tem aparentemente tido pouco impacto na redução do influxo de migrantes não-documentados (Kossoudji, 1990; Martin e Widgren, 1996,p.22).

Existe um corpo emergente de opinião que sugere que o controle da imigração é melhor resolvidona sua fonte (ex: ver Martin e Widgren, 1997) endereçando os imperativoseconômicos queimpelem a migração em primeiro lugar. Estas estratégias poderiam envolver elementos tais como:

* Desenvolvimento da assistência dos países de destino para com os de origem, talvez tendo como alvo as principais regiões de origem das migrações ilegais no país de origem.

*Investimento estrangeiro direto do país de destino para o país de origem para criar oportunidades de empregos alternativos nas áreas de origem.
* Preferências comerciais onde o país de destino dá uma preferência particular aos produtos do país de origem, especialmente daqueles oriundos das áreas de migração.

Tais estratégias têm como objetivo superar os fatores de expulsão, operando nos países de origem e podem de alguma forma ser de longo prazo em seus impactos. De fato, a evidência sugeriria que, inicialmente, um aumento no desenvolvimento nas áreas de origem conduziria a um aumento nos níveis de migração (Massey, 1990). Martin (1993) tem concordado que existe uma transição na migração, por meio da qual nos primeiros estágios da liberalização da economia e rápido crescimento econômico, as mudanças estruturais deslocarão os trabalhadores, bem como continuará ocorrendo um incremento da força de trabalho, porque a transição demográfica nãoestará concluída. Por isso, há um excesso significativo de mão-deobra, resultando nas pressões emigratórias. Contudo, conforme o desenvolvimento, progressos e crescimento populacionais diminuem, a emigração começa a diminuir, e haverá, eventualmente, escassez de mão-de-obra. A Coréia do Sul constitui um exemplo de tal transição, sendo uma fonte significativa de mão-de-obra migrante para o Oriente Médio e outros lugares, bem como de residentes permanentes para os Estados Unidos e outros lugares nos anos 70,80 , sendo, porém, no final dos anos 80 e 90 , alvo de imigração, tanto legal quanto ilegal. De forma questionável, pode-se afirmar que a migração dos anos 80 e 70 contribuiu para o rápido desenvolvimento daquele período.

Claramente a causa de muitas migrações ilegais é a pobreza e as grandes diferenças internacionais em termos do bemestar das pessoas que só será resolvido por meio da melhoria da vida das pessoas nas áreas de origem. Em muitos casos as migrações internacionais ilegais representam uma das poucas opções que as pessoas nas regiões pobres têm disponivel para melhorar sua situação. Negá-las é cortar uma das poucas saídas para o desenvolvimento das áreas locais.

Um dos principais dilemas no trato com as migrações ilegais está relacionado ao fato de que as intervenções do tipo 
"batidas policiais" fazem mais mal às vítimas (migrantes) que aos criminosos (recrutadores, empregadores etc.). Migrantes individuais sofrerão consideravelmente com o resultado de ser preso e deportado, enquanto que todo o processo de migração continuará desimpedido com os recrutadores e os empregadores não sendo afetados. Se existe uma demanda significativa por trabalho nas áreas de destino é preferível que alguma forma de legislação seja obtida. Esta mudança geralmente precisa começar no país de origem, onde o processo de imigração legal torna-se mais simples, barato e transparente. No presente, em muitos países o processo está por demais burocratizado e designado em maximizar as oportunidades de extrair cobranças não-oficiais de migrantes potenciais do que em expedir e facilitar o processo de migração. Tanto quanto possível legalizar o processo de migração é, de longe, a mancira mais efetiva de lidar com o problema da migração ilegal. Isto certamente expulsará o elemento criminoso na indústria da imigração e diminuirá as chances de exploração dos trabalhadores. É a parte criminosa da indústria de imigração que é o crime real na migração não-documentada e deve ser o alvo da "batida policial" e das políticas de controle e programas na origem e no destino.

Um dos itens mais importantes com respeito à migração não-documentada está relacionado com o bem-estar e direitos dos migrantes. Migrantes são tendencialmente mais vulneráveis às várias formas de exploração do que os não-migrantes dado que eles em geral não têm todos os direitos de cidadãos no destino e também têm a desvantagem de não terem o conhecimento dos costumes e práticas locais, além das barreiras de linguagem e culturais. Entretanto, o status ilegal da migração nãodocumentada adiciona consideravelmente mais a sua vulnerabilidade. Exploração e trapaceamento de migrantes ilegais é comum e pode ocorrer em um grande número de situações:

* no processo de recrutamento - cobrando a mais e encaminhando os migrantes para empregos não existentes ou diferentes do prometido;

* na viagem para o destino - cobrando a mais e lotando os navios ou outros meios de transporte;

* no destino - falta de pagamento, pagamento abaixo do combinado ou atraso no pagamento de salários, más condições de trabalho, más condições de alojamento, horas excessivas de trabalho, roubo das remessas mandadas para suas familias;

* no momento da volta - não pagamento de todos os salários, a entrega do migrante às autoridade para economizar com os custos da viagem de volta, roubo de dinheiro e presentes.

A sempre presente ameaça de ser entregue às autoridade põe o migrante ilegal em uma constante situação de perigo tornando-o vulnerável a todo tipo de exploração. O migrante ilegal é de difícil proteção pelo fato de estar fora da jurisdição da Nação na qual tem cidadania. No entanto, esforços devem ser feitos para providenciar adequada proteção aos direitos dos migrantes não-documentados e trabalhadores migrantes. Uma regulamentação internacional está sendo montada para prover uma estrutura para tal na ILO (International Labour Office - Convenções sobre Trabalhadores Migrantes). Contudo, poucos países têm ratificado essas convenções - na Ásia, por exemplo, só os dois países que enviam migrantes assinaram: Filipinas e Sri Lanka.

Se o migrante está em uma situação dupla de insegurança dado o seu status de migrante e ilegal, o aumento do número de mulheres envolvidas nesse processo as expõem a uma situação de tripla insegurança por causa da questão do gênero, havendo um risco ainda maior de exploração. Globalmente está havendo uma feminização da migração internacional, nas últimas duas décadas, dado que o número de migrantes mulheres é tão grande quanto de homens (United Nations, 1997). Este padrão certamente tem sido verdadeiro tanto para migração não-documentada quanto para o movimento legal. Exploração de mulheres pode não só assumir as formas listadas acima, mas também pode envolver a exploração sexual de diversos tipos. O risco é exacerbado pelos tipos de empregos a que muitas das migrantes ilegais se destinam. Muitas trabalham como empregadas domésticas e como tal estão fora do alcance das leis trabalhistas da nação hospedeira. Por exemplo, muitas mulheres da Indonésia vão para a Arábia Saudita sob um visto de peregrinação (umroh) mas permanecem em trabalhos ilegais. Histórias de assédio sexual e outras formas de agressão dessas mulheres aparecem quase que diariamente na imprensa Indonesiana, porém, os representantes do governo da Indonésia na Arábia Saudita não têm poder para intervir. Outras mulheres estão envolvidas na indústria do entretenimento e estão sob constante ameaça de exploração. Enquanto algumas migrantes migram já sabendo que vão trabalhar na industria sexual no destino, outras são enganadas inicialmente e depois forçadas a trabalhar como prostitutas. Urge a necessidade de programas e políticas efetivas para proteger a migrante e especialmente a migrante trabalhadora (Lim and Oishi, 1996). O crescimento da indústria do tráfico de mulheres e crianças precisa ser enfrentadovigorosamente onde está ocorrendo.

\section{CONCLUSÃO}

Migrações não-documentadas estão acontecendo em níveis sem precedentes e continuarão a crescer em escala e impacto, conforme as forças da globalização se tornarem mais penetrantes e a fricção da distância separando as nações estiver mais erodida. Uma estimativa calcula o número de pessoas contrabandeadas dos países pobres para os ricos em termos de um milhão por ano (The Straits Times, 14 junho, 1994). A crescente força e persistência tanto das redes sociais de migrações quanto da indústria da imigração asseguram que o processo continuará, assim como o fato de muitos dos países com carência de mão-de-obra permenecerão endurecendo sua posição contra a aceitação de trabalhadores estrangeiros. Toda experiência anterior sugere que onde significativas oportunidades de emprego existirem, os migrantes acharão uma trilha para alcançá-las, apesar da extensão e sofisticação das medidas de controle introduzidas pelos países de destino.

Muito do temor dos países receptores consiste no fato de que a maior parte dos migrantes tenha a intenção de se estabele- 
cer. Este é o paradigma da migração internacional que foi dominante por mais de um século e prevaleceu até as primeiras décadas do pós-guerra. Contudo, no mundo contemporâneo tem-se que questionar se o povoamento é ainda um paradigma dominante. Com o encolhimento da distância causada pelos modernos meios de comunicação e o barateamento das viagens internacionais, o movimento de não-permanência está se tornando predominante. Deve-se ao menos questionar se a maioria dos trabalhadores migrantes contemporâneos da Ásia vai querer permanecer no Oriente Médio se lhes for dada a oportunidade exatamente como ocorreu, por exemplo, com os trabalhadores turcos que permaneceram na Alemanha nos anos 60 . Neste final de década tem-se uma situação na qual é possível para os migrantes ficarem períodos consideráveis em um país de destino, mas ainda manter o contato com suas famílias e ligações principais com seu país de origem. De fato, pode acontecer que suas remessas contribuam para erodir as razões originais de sua migração, através da ajuda ao desenvolvimento que aumenta acentuadamente as oportunidades e bem-estar no país de origem. Infelizmente o nosso conhecimento da natureza, causas e impactos da migração internacional nãodocumentada é tão mínima que não podemos prover aos atores políticos conselhos definitivos nesta área.

* Graeme Hugo é Professor de Geografia da Universidade de Adelaide.

AZIZAH, K.

\section{BIBLIOGRAFIA}

(1997) International Migration and Its Impact on Malaysia. Paper presented at 11th Asia-Pacific Roundtable, Labour Migration in Southeast Asia: The Impact (Political, Economic, Social, Security), Kuala Lumpur, 5-8 June.

BEARE, M. E

(1977) Framework Paper: Illegal Migration. Prepared for the CSCAP Study Group on Transnational Crime, Bangkok, Thailand, October. BEHAR, R.

(1990) The Price of Freedom, Time, 14 May, pp.2628.

BILSBORROW, R.E.; HUGO, G.; OBERAI, A. S. and

ZLOTNIK, H.

(1997) International Migration Statistics: Guidelines for Improving Data Collection Systems, International Labour Office, Geneva.

BUSTAMANTE, J. A.

(1997) Mexico-United States labour migration: some theoretical and methodological innovations and research findings. Pp. 45-91 in IUSSP International Population Conference Beijing 1997, Volume 1. IUSSP, Liege.

ESPENSHADE, T. J.
(1990) A Short History of U.S. Policy Toward Illegal Immigration, Population Today, v. 18, n² 2, pp.6-9. GOOI, K

(1993) Cry of the Innocents, Far Eastern Economic Review, 9 September, pp.36-37.

GOSS, J. and LINDQUIST, B.

(1995) Conceptualizing International Labour Migration: A Structural Perspective, International Migration Review, vol. 29, $\mathrm{n}^{\circ} 2$, pp.317-351.

HOEFER, M. D.

(1989) Characteristics of Aliens Legalising Under IRCA. Paper presented at the Annual Meeting of the Population Association of America, Baltimore, Maryland, March 29.

HUGO, G. J.

(1993) Indonesian Labour Migration to Malaysia: Trends and Policy Implications. Southeast Asian Journal of Social Science, vol. 21, $n^{\circ} 1, \mathrm{pp} .36-70$.

HUGO, G. J.

(1994) Demographic and spatial aspects of immigration. Pp. 30-110 In: M. Wooden, R. Holton, G. Hugoand J. Sloan (eds.) Australian Immigration: A Survey of the Inssues, AGPS, Canberra.

HUGO, G. J.

(1995) Illegal International Migration in Asia, pp. 397-402 In: R. Cohen (ed.), Cambridge Survey of World Migration, Cambridge University Press, Cambridge.

HUGO, G. J.

(1996) Economic Impacts of International Labour Emigration on Regional and Local Development: Some Evidence from Indonesia. Paper presented at the Annual Meeting of the PAA, New Orleans, May

HUGO, G. J.

(1997a) Migration and Female Empowerment, Paper prepared for International Union for the Scientific Study of Population's Committee on Gender and Population's Seminar on Female Empowerment and Demographic Processes: Moving Beyond Cairo, Lund, Sweden, 21-24 April.

HUGO, G. J.

(1997b) ASEAN on the move: The Mobilisation of South-east Asia's Population. Paper prepared for Seminar on "Development and Change: Thirty Years of ASEAN" organised by Division of Geography, Nanyang Technological University, Singapore, 8 November.

HUGO, G. J.

(1998) Migration and Mobilisation in Asia: An Overview. Chapter in E. R. Laquian, A.A. Laquian and T. McGee (eds.) The Silent Debate: Asian Immigration and Racism in Canada, Institute of Asian Research, University of British Columbia, Vancouver.

HUGO, G. J. and SINGHANETRA-RENARD, A. (1991) International Migration of Contract Labour in Asia: Issues and Implications, IRDC, Ottawa.

KOSSOUDJI, S. A

(1990) Playing Cat and Mouse at the Border: Does the INS Alien Apprehension Strategy Alter the Aggregate Supply of Illegal Labour? Paper presented at Annual Meeting of the Population Association of America.

LIM, L. L. and OISHI, N.

(1996) International Migration of Asian Women: Distinctive Characteristics and Policy Concerns, in G. Battistella and A. Paganoni (eds.), Asian Women in Migration, Scalabrini Migration Centre, Quezon City, pp.23-54

LINTNER, B.

(1997) Reaching Out, Far Eastern Economic Review, 11 September, pp.57-58.

LINTNER, B. and SAEN, C.

(1994) River of Dreams, Far Eastern Economic Review, 22 December, p. 26.

LOWELL, B. L.

(1992) Circular Mobility, Migrant Communities and Policy Restrictions: Unauthorised Flows from
Mexico, Immigration Policy and Research Working Paper 13, U.S. Department of Labor, Bureau of International Labor Affairs, Washington.

MARTIN, P. L.

(1993) Trade andMigration: NAFTA and Agriculture, Washington DC, Institute for International Economics.

MARTIN, P. and WIDGREN, J.

(1996) International Migration: A Global Challenge, Population Bulletin, vol.51, $\mathrm{n}^{\circ} 1$

MASSEY.D. S.

(1990) The Social and Economic Origins of Immigration. Annals of the American Academy of Political and Social Science, vol.510, pp.60-72.

MASSEY, D.S.; ARANGO, J.; HUGO, G.; KOUAOUCI,

A.: PELLEGRINO, A and TAYLOR, J.E.

(1993) Theories of International Migration: AReview and Appraisal, Population and Development Review, vol.19, $\mathrm{n}^{\circ} 3, \mathrm{pp} .431-466$.

MOONEY, P.; ZYLA, C. and ZYLA, M.

(1993) Braving the Seas and More, Far Eastem Economic Review, 8 April, pp.17-19.

PRASAI, S. B.

(1993) Asia's Labour Pains. Far Eastern Economic Review, 29 April.

PRIORI, M. J.

(1979) Birds of Passage, Migrant Labour and Industrial Societies, Cambridge University Press, Cambridge.

ROBERTS, K. D.

(1997) China's "Tidal Wave" of Migrant Labor: What can we learn from Mexican undocumented migration to the United States, International Migration Review, vol.31, $n^{\circ} 2$, pp.249-293.

SAKAMAKI, S.

(1994) Stateless Children. Far Eastern Economic Review, January 20, p.38.

SASSEN, $\mathbf{S}$

(1993) Internationalisation: The New Migration in Japan and the United States, International Migration, vol. 31, $\mathrm{n}^{\circ} 1$, pp.73-103.

SAYWELL, $T$.

(1997) Workers Offensive. Far Eastern Economic Review, 29 May, pp.50-52.

SKROBANEK, S.; BOONPAKDI, N. and JANTHAKEERO, C.

(1997) The Traffic in Women - Human Realities of the International Sex Trade, Zed Books, London.

SMITH, P. J.

(1997) Human Smuggling: Chinese Migrants Trafficking and the Challenge to America's Immigration Tradition, Center for Strategic and International Studies, Washington

SPENCER, S

(1992) Illegal Migrant Labourers in Japan, International Migration Review, vol. 26, $\mathrm{n}^{\circ} 3, \mathrm{pp}$. 754-786

SULLNAN, G.; GUNASEKARAN, S, and SIENGTHAI, S. (1992) Labour Migration and Policy Formation in a Newly Industrialised Country, ASEAN Economic Bulletin, vol.9, $\mathrm{n}^{\circ} 1$, pp.137-154.

TODARO, M. P

(1986) A Theory of Illegal International Migration from Developing Countries. Center for Policy Studies Working Papers $n^{\circ} 126$, The Population Council, New York.

UNITED NATIONS (UN)

(1997) Draft World Population Monitoring, 1997. Preliminary version prepared by the Population Division of the Department for Economic and Social Information and Policy Analysis of the United Nations Secretariat. United Nations, New York.

ZENG, $Y$

(1998) Conditions in China Influencing OutMigration to Other Countries. Chapter in E.R. Laquian, A.A. Laquian and T. McGee (eds.) The Silent Debate: Asian Immigration and Racism in Canada, Institute of Asian Research, University of British Columbia, Vancouver. 